\title{
Physical activity to prevent falls in older people: time to intervene in high risk groups using falls as an outcome
}

Fall related injuries and the resulting deaths in older adults are a major, and increasing, health problem world wide. ${ }^{1-3}$ About $30 \%$ of people over 65 years of age fall at least once a year, and about half of these do so recurrently. ${ }^{134} \mathrm{~A}$ fall may result in a fracture, particularly in an older person, and about $90 \%$ of hip fractures result from falls. ${ }^{5}$ The outcome of a hip fracture is fatal in $12-20 \%$ of cases. ${ }^{6}$ The annual cost of fall related fractures in the United States is estimated to be $\$ 10$ billion. ${ }^{7}$ Furthermore, the incidence of hip fractures continues to rise steadily, even when age adjusted figures are used. ${ }^{12}$

There are many causes of falls, and they are reviewed in detail elsewhere. ${ }^{8}{ }^{9}$ Some of the major categories of risk factors for falling are:

- General physical functioning

- Gait, balance, and physical performance

- Musculoskeletal and neuromuscular measures

- Demographic factors-for example, age, race

- Sensory impairments

- Medical conditions

- Indicators of general health

- Medication use

- Psychological, behavioural, social, and environmental factors

Even a cursory scan of this list discloses many modifiable factors. ${ }^{10}$ Therefore strategies for injury prevention may have an important role in alleviating the problem of fall related injuries. Training that involves strength, balance, and improved transfer must form part of an optimum intervention strategy to prevent falls. ${ }^{112}$ This editorial aims to highlight opportunities for sports medicine clinicians and scientists who wish to work in a multidisciplinary research setting to limit the epidemic of injuries from falls in the elderly. We discuss research approaches at four overlapping levels of inquiry: basic science, applied science, clinical trials, and health services.

\section{Basic research into biological mechanisms}

Basic scientific research into fall prevention is concerned with the mechanisms that control balance, particularly in nerves and muscles. Balance relies on central nervous system integration of the somatosensory, vestibular, and visual systems, and basic science researchers are unravelling this process. For example, new techniques have been developed to measure the potentials that pass along sensory nerves to the vestibular system. ${ }^{13}$ Researchers are investigating how sensory nerves age and whether their signals to the central nervous system can be improved with training. Similarly, muscle physiologists are evaluating the cellular mechanisms that may explain the slower peak forces generated by ageing muscle. ${ }^{1415}$

\section{Applied research into the mechanisms that underlie falls}

Applied scientific research into fall prevention looks at areas such as the role of gait in fall risk, ${ }^{16}$ fall recovery mechanisms, and fall strategies to minimise injury. ${ }^{17}$ Slow gait is a well established, but remediable, fall risk factor.
Fall recovery refers to the ability to avoid falling after tripping or stumbling. ${ }^{17}$ The rationale behind strategies of falling arose from data showing that hip fractures are usually the result of falls on to the greater trochanter region. ${ }^{5}$ Thus, if people can learn to fall in a way that avoids this contact, a hip fracture may be prevented. Acting on the notion that not all falls can be prevented, however, Finnish sports medicine researchers recently reported in the New England fournal of Medicine that a specific hip protector reduced fractures in high risk residents of nursing homes. ${ }^{18}$

\section{Multifactorial clinical trials powered to study falls as an outcome measure}

There is an urgent need for more good quality clinical trials implementing multifactorial interventions to prevent falls in high risk community and nursing home populations. Multifactorial interventions include rationalisation of medication, physical training to improve strength, balance, and transfers, and removal of hazards in the home that may cause falls. ${ }^{12} 19$

A large number of clinical trials have examined the effect of various interventions on fall risk factors. ${ }^{9}$ Fall risk factors - for example, reduced sway, muscle weaknessserve as a surrogate measure of falls and permit investigators to enroll fewer subjects for a shorter period of time than would be needed to measure falls themselves. Only a dozen randomised controlled interventions have measured falls as the primary outcome. ${ }^{311}$ We believe that clinical trials must now focus on falls as an outcome. Learning from the bone health field, we note that surrogate outcome measures have variously underestimated ${ }^{20}$ and overestimated $^{21}$ the effects of an intervention on the outcome in question. Pharmaceutical trials in prevention of osteoporosis fractures gained credence when they showed fracture reduction, not just improvements in the surrogate - that is, bone mass. ${ }^{22}$

Thus clinical trials of fall intervention must be powered sufficiently to measure falls as a primary outcome measure. Clearly the more at risk the population is of falling, the smaller the number of subjects that must be studied. The classic (and successful!) clinical trials of fall intervention have recruited 30070 year olds ${ }^{12}$ and 23080 year olds. ${ }^{19}$ Such studies cost around \$US150 000-250 000 and are eminently fundable given the costs resulting from fractures, nursing home care, and death. ${ }^{23}$

\section{Involvement of health care services and policy academics in research into fall prevention}

Many fall related injuries have well documented health costs - for example, the direct cost of a hip fracture treated in the United States is \$US30 000. Furthermore, interventions for fall prevention lend themselves to implementation as public health policy. Thus, there is an urgent need for physical activity researchers to collaborate with scientists and administrators in the health policy and services field. Australian researchers showed that a community based intervention of public education and increased awareness of fall risk factors reduced self reported fall rates by $22 \%$ and fall related hospital stay by $20 \% .{ }^{24}$ This intervention 
reached roughly $40000-60000$ people at a total cost of $\$ A 600000$. The study did not report potential cost effectiveness of this intervention. To date, no falls prevention study has had sufficient power to show a reduction in serious injuries from falls such as fractures. However, some studies of falls prevention intervention reported a reduction in health care use as a result of the intervention. ${ }^{3}$

\section{Fall prevention research in the at risk elderly is fertile ground for "sports" medicine}

The term "sports" medicine was a useful one in the 1970 s as this field emerged, but it is now much too narrow for a discipline that embraces the health benefits of physical activity and exercise. The British Association of Sport and Medicine (BASM) changed its name to the British Association of Sport and Exercise Medicine (BASEM) for precisely this reason. Narrowly defined "sports" medicine research may be some way from intervention to prevent fall related fractures in 90 year old people, but, in truth, exercise medicine may be the most potent treatment for exactly this age group. Appropriately prescribed exercise can at once reduce major fall risk factors ${ }^{25}$ by improving upper and lower limb strength, balance, coordination, transfer skills, and reaction to environmental hazards. Physical activity may also reduce the need for sedative medications. Therefore the best methods of fall prevention may involve expert exercise prescription with qualified supervision, rather than a pharmaceutical agent.

We encourage the exercise medicine clinician and researcher to tackle the problem of fall prevention as many of our colleagues have already done. ${ }^{38}{ }^{26-28}$ Given the enormous financial burden that fall related injuries place on government coffers, there is no doubt that granting agencies will continue to fund this important area of research. Physical activity researchers can play a pivotal role in this research as all the successful studies of multifactorial fall prevention to date have had a physical training programme at their core. ${ }^{12}{ }^{19}$

K M KHAN T LIU-AMBROSE M G DONALDSON

fames Mather Building

H A MCKAY

5804 Fairview Avenue

Vancouver V6T 1Z3, Canada

1 Kannus P, Niemi S, Parkkari J, et al. Hip fractures in Finland between 1970 and 1997 and predictions for the future. Lancet 1999;353:802-5.

2 Kannus P, Palvanen M, Niemi S, et al. Epidemiology of osteoporotic pelvic fractures in elderly people in Finland: sharp increase in 1970-1997 and alarming projections for the new millennium. Osteoporos Int 2000;11:443-
3 Gardner MM, Robertson MC, Campbell AJ. Exercise in preventing falls and fall related injuries in older people: a review of randomised controlled trials. Brf Sports Med 2000;34:7-17.

4 Tinetti ME, Lui WL, Claus E. Predictors and prognosis of instability to get up after falls among elderly persons. $7 A M A$ 1993;269:65-70.

5 Parkkari J, Kannus P, Palvanen M, et al. Majority of hip fractures occur as a result of a fall and impact on the greater trochanter of the femur: a prospective controlled hip fracture study with 206 consecutive patients. prospective controlled hip fract
Calcif Tissue Int 1999;65:183-7.

6 Peck WA, Riggs BL, Bell NH, et al. Research directions in osteoporosis. $N$ Engl f Med 1988;85:275-82.

7 Cummings SR, Rubin SM, Black D. The future of hip fractures in the United States. Clin Orthop 1990;252:163-6.

8 Lord SR, Sherrington C, Menz HB. Falls in older people: risk factors and strategies for prevention. Cambridge: Cambridge University Press, 2001.

9 Myers AH, Young Y, Langlois JA. Prevention of falls in the elderly. Bone 1996;18:87S-101S.

10 Cummings SR, Nevitt MC. Falls. N Engl F Med 1994;331:872-3.

11 Carter N, Kannus P, Khan KM. Exercise and the prevention of falls in older adults: a systematic literature review of the rationale and the evidence. Sports Med 2001;31:427-38.

12 Tinetti ME, Baker DI, McAvay G. A multifactorial intervention to reduce the risk of falling among elderly people living in the community. N Engl F Med 1994;331:821-7.

13 Inglis JT, Leeper JB, Wilson LR, et al. The development of conduction block in single human axons following a focal nerve injury. F Physiol (Lond) 1998; 513:127-33.

14 Hurley BF, Roth SM. Strength training in the elderly: effects on risk factors for age-related diseases. Sports Med 2000;30:249-68.

15 Ryushi T, Kumagai K, Hayase $\mathrm{H}$, et al. Effect of resistive knee extension training on postural control measures in middle aged and elderly persons. Fournal of Physiology, Anthropology and Applied Human Sciences 2000;19: 143-9.

16 Eng JJ, Winter DA, Patla AE. Intralimb dynamics simplify reactive control strategies during locomotion. F Biomech 1997;30:581-8.

17 Robinovitch SN, Hsiao ET, Sandler R, et al. Prevention of falls and fall-related fractures through biomechanics. Exerc Sport Sci Rev 2000;28: $74-9$.

18 Kannus P, Parkkari J, Niemi S, et al. Prevention of hip fracture in elderly people with use of a hip protector. N Engl F Med 2000;343:1506-13.

19 Campbell AJ, Roberton MC, Gardner MM, et al. Randomized controlled trial of a general practice programme of home based exercise to prevent falls in elderly women. $B M 7$ 1997;315:1065-9.

20 Chesnut $\mathrm{CH}$, 3rd, Silverman S, Andriano K, et al. A randomized trial of nasal spray salmon calcitonin in postmenopausal women with established osteoporosis: the prevent recurrence of osteoporotic fractures study. PROOF Study Group. Am f Med 2000;109:267-76.

21 Riggs BL, O'Fallon WM, Lane A, et al. Clinical trial of fluoride therapy in postmenopausal osteoporotic women: extended observations and additional analysis. F Bone Miner Res 1994;9:265-75.

22 Ensrud KE, Black DM, Palermo L, et al. Treatment with alendronate prevents fractures in women at highest risk: results from the Fracture Intervention Trial. Arch Intern Med 1997;157:2617-24.

23 Rizzo JA, Baker DI, McAvay G, et al. The cost-effectiveness of a multifactorial targeted prevention program for falls among community elderly

24 Kempton A, Van Beurden E, Sladden T, et al. Older people can stay on their feet: final results of a community-based falls prevention program. Health Promot Internation 2000;15:27-33.

25 Nelson ME, Fiatarone MA, Morganti CM, et al. Effects of high-intensity strength training on multiple risk factors for osteoporotic fractures: a randomized controlled trial. FAMA 1994;272:1909-14.

26 Lord SR, Ward JA, Williams P, et al. The effect of a 12-month exercise trial on balance, strength, and falls in older women: a randomized controlled study. F Am Geriatr Soc 1995;43:1198-206.

27 Kannus P, Parkkari J, Koskinen S, et al. Fall-induced injuries and deaths among older adults. $\mathcal{F A M A}$ 1999;281:1895-9.

28 Taunton JE, Martin AD, Rhodes EC, et al. Exercise for the older woman: choosing the right prescription. Br F Sports Med 1997;31:5-10.

Please note that the editorial office of British Fournal of Sports Medicine has moved. Please send all future communications to: Dr Paul McCrory, British Fournal of Sports Medicine, Centre for Sports Medicine Research \& Education School of Physiotherapy Level 1, 200 Berkeley Street, Parkville, Victoria 3052, Australia. Tel: +61 38344 4118; Fax: +61 38344 3771; Email: bjsm@bmigroup.com 